\title{
Risk factors associated with the antimicrobial resistance of Staphylococcus aureus isolated from bovine mastitis ${ }^{1}$
}

\author{
Daniele C. Beuron², Cristina S. Cortinhas², Bruno G. Botaro², Susana N. Macedo², \\ Juliano L. Gonçalves ${ }^{2}$, Maria A.V.P. Brito ${ }^{3}$ and Marcos V. Santos ${ }^{2 *}$
}

\begin{abstract}
Beuron D.C., Cortinhas C.S., Botaro B.G., Macedo S.N., Gonçalves J.L., Brito M.A.V.P. \& Santos M.V. 2014. Risk factors associated with the antimicrobial resistance of Staphylococcus aureus isolated from bovine mastitis. Pesquisa Veterinária Brasileira 34(10):947-952. Departamento de Nutrição e Produção Animal, Faculdade de Medicina Veterinária e Zootecnia, Universidade de São Paulo, Av. Duque de Caxias Norte 225, Pirassununga, SP 13635-900, Brazil.E-mail: mveiga@usp.br

The objective of this study was to evaluate herd management practices and mastitis treatment procedures as risk factors associated with Staphylococcus aureus antimicrobial resistance. For this study, 13 herds were selected to participate in the study to evaluate the association between their management practices and mastitis treatment procedures and in vitro antimicrobial susceptibility. A total of 1069 composite milk samples were collected aseptically from the selected cows in four different periods over two years. The samples were used for microbiological culturing of $S$. aureus isolates and evaluation of their antimicrobial susceptibility. A total of 756 samples (70.7\%) were culture-positive, and S. aureus comprised $27.77 \%(\mathrm{n}=210)$ of the isolates. The $S$. aureus isolates were tested using the disk-diffusion susceptibility assay with the following antimicrobials: ampicillin 10mg; clindamycin $2 \mu \mathrm{g}$; penicillin $1 \mathrm{mg}$; ceftiofur $30 \mu \mathrm{g}$; gentamicin $10 \mathrm{mg}$; sulfa-trimethoprim $25 \mu \mathrm{g}$; enrofloxacin $5 \mu \mathrm{g}$; sulfonamide $300 \mu \mathrm{g}$; tetracycline $30 \mu \mathrm{g}$; oxacillin $1 \mathrm{mg}$; cephalothin $30 \mu \mathrm{g}$ and erythromycin $5 \mu \mathrm{g}$. The variables that were significantly associated with $S$. aureus resistance were as follows: the treatment of clinical mastitis for ampicillin (OR=2.18), dry cow treatment for enrofloxacin $(\mathrm{OR}=2.11)$ and not sending milk samples for microbiological culture and susceptibility tests, for ampicillin $(\mathrm{OR}=2.57)$ and penicillin $(\mathrm{OR}=4.69)$. In conclusion, the identification of risk factors for $S$. aureus resistance against various mastitis antimicrobials is an important information that may help in practical recommendations for prudent use of antimicrobial in milk production.
\end{abstract}

INDEX TERMS: Risk factors, antimicrobial resistance, Staphylococcus aureus, mastitis, treatment, management practices, in vitro susceptibility.

RESUMO.- [Fatores de risco associados com a resistência antimicrobiana de Staphylococcus aureus isolados da mastite bovina.] Objetivou-se com este estudo avaliar os fatores de risco associados às práticas de manejo e tratamento de mastite e a resistência aos antimicrobianos de Staphylococcus aureus isolados de vacas com mastite. Fo-

\footnotetext{
${ }^{1}$ Received on Januray 20, 2014.

Accepted for publication on August 28, 2014.

${ }^{2}$ Departamento de Nutrição e Produção Animal, Faculdade de Medicina Veterinária e Zootecnia (FMVZ), Universidade de São Paulo (USP), Av. Duque de Caxias Norte 225, Pirassununga, SP 13635-900, Brazil. E-mail: mveiga@usp.br

${ }^{3}$ Embrapa Gado de Leite, Rua Eugênio do Nascimento 610, Dom Bosco, Juiz de Fora, MG 36038-330, Brazil.
}

ram selecionados para o presente estudo 13 rebanhos localizados na região de Pirassununga/SP. Foi aplicado um questionário contendo informações para o levantamento de fatores de risco relacionados à resistência aos antimicrobianos e às práticas de manejo e tratamento de mastite. Após a seleção dos rebanhos e aplicação dos questionários, foram utilizados 210 isolados de $S$. aureus de amostras compostas de leite coletadas durante 24 meses, em quatro períodos, para realização dos testes de resistência. Os antimicrobianos testados foram: ampicilina $10 \mu \mathrm{g}$, clindamicina $2 \mu \mathrm{g}$, penicilina $1 \mu \mathrm{g}$, eftiofour $30 \mu \mathrm{g}$, gentamicina $10 \mu \mathrm{g}$, sulfatrimetropin $25 \mu \mathrm{g}$, enrofloxacina $5 \mu \mathrm{g}$, sulfonamida $300 \mu \mathrm{g}$, tetraciclina $30 \mu \mathrm{g}$, oxacilina $1 \mu \mathrm{g}$, cefalotina $30 \mu \mathrm{g}$ e eritromicina $5 \mu \mathrm{g}$. As variáveis que foram significativamente as- 
sociadas à resistência de $S$. aureus foram: o tratamento da mastite clínica para ampicilina $(\mathrm{OR}=2,18)$, o tratamento da vaca seca para enrofloxacina $(\mathrm{OR}=2,11)$, e o não envio de amostras de leite para a cultura microbiológica e testes de sensibilidade, para ampicilina $(\mathrm{OR}=2,57)$ e penicilina $(\mathrm{OR}=4,69)$. Em conclusão, a identificação dos fatores de risco para a resistência $S$. aureus frente aos principais agentes antimicrobianos, utilizados para tratamento da mastite, pode auxiliar o estabelecimento do uso prudente de antimicrobianos na produção de leite.

TERMOS DE INDEXAÇÃO: Fatores de risco, resistência antimicrobiana, Staphylococcus aureus, mastite bovina, tratamento, práticas de manejo, in vitro susceptibilidade.

\section{INTRODUCTION}

Mastitis is the most common disease in dairy herds and is the main cause of antibiotic use in adult dairy cows (Ruegg 2009). On dairy farms, antimicrobials such as penicillin, cephalosporin, and tetracycline, among others, are used to treat and prevent mastitis that is caused by Gram-positive and Gram-negative bacteria (Oliver \& Murinda 2012). However, the efficacy of these antimicrobials can be compromised by the emergence of antimicrobial resistance in the relevant mastitis pathogens, such as Staphylococcus aureus. The intensive use of antibiotics in human and veterinary medicine may increase bacterial resistance (Hawkey 2003). Thus, dairy farms and the current management practices employed for milk production might be associated with the dissemination of antibiotic-resistant bacterial strains (Acar \& Moulin 2006).

Staphylococcus aureus is one of the most important causes of clinical mastitis and is the pathogen that is most frequently isolated in cases of subclinical mastitis worldwide (Sampimon et al. 2009, Waage 1997). S. aureus is also the main microorganism investigated in antimicrobial susceptibility studies due to its high prevalence in dairy cow mastitis (Malinowski et al. 2002). Additionally, staphylococcal food poisoning is caused by the ingestion of staphylococcal enterotoxins, which are resistant to heat treatment and are generally produced by $S$. aureus strains (Roberson et al. 1994). Thus, $S$. aureus is responsible for major losses on dairy farms and is resistant to several of the antimicrobials that are routinely used in mastitis treatment (Freitas et al. 2005). Several mechanisms of resistance to the available antimicrobial drugs have been described; however, many aspects of antimicrobial resistance development and dissemination remain uncertain. Resistance among mastitis pathogens has been reported for nearly four decades, but despite this, there is no scientific evidence to determine whether it is an emergent phenomenon or is in progress (Oliver et al. 2011).

Some studies have evaluated the trends of antimicrobial resistance of mastitis-causing bacteria for various periods of time in different regions (Erskine et al. 2002, Myllys et al. 1998, Petrovski et al. 2011). The results of these studies indicated variation among the different regions studied; however, there is no scientific evidence of a significant increase in the antimicrobial resistance of mastitis-causing pathogens over time (Oliver et al. 2011). Some studies have reported that the susceptibility of $S$. aureus varied from 7 to $63 \%$ for penicillin (Guler et al. 2005, Watts \& Salmon 1997) from 0 to $93 \%$ for erythromycin (Wang et al. 2008), from 0 to 28\% for tetracycline (Guler et al. 2005, Watts \& Salmon 1997), and from 4.5 to $7.5 \%$ for sulfadimethoxine (Makovec et al. 2003, Sabour et al. 2004). However, no studies concerning the management- and treatment-associated risk factors for the antimicrobial resistance of $S$. aureus in bovine mastitis are available. The objective of this study was to evaluate the association between the management practices and treatment procedures and the antimicrobial resistance of $S$. aureus that was isolated from bovine mastitis samples.

\section{MATERIALS AND METHODS}

\section{Selection of dairy herds and cow sampling}

Thirteen out of 60 dairy herds from the members of the dairy industry located in Pirassununga (São Paulo State, Brazil) were selected according the number of lactating cows per herd, the herd's milk production, a maximum distance of $80 \mathrm{~km}$ from the laboratory where the evaluation was performed and the farmers' willingness to participate in this study. Selected dairy herds were randomly selected in the municipalities of Leme, Santa Rita do Passa Quatro, Descalvado, São João da Boa Vista and Pirassununga.

To determine the total number of herds to be included in this study, the number of milk samples required to estimate the frequency of Staphylococcus spp. antimicrobial resistance according to the recommendations described by the OIE (2008) was considered. A variation in the prevalence of $S$. aureus antimicrobial resistance to penicillin of $35 \%$ (90\% confidence interval: $33.4-$ $36.7 \%$ ) was used, based on the results reported by Brito et al. (1999). The number of milk samples collected per herd was based on the methodology of Frankena \& Graat (1997) (Table 1).

The on-farm data about the possible risk factors associated with antimicrobial susceptibility were collected during the first farm visit based on a questionnaire that included questions about mastitis treatment, prevention procedures, and herd management. Milk samples were collected on four different occasions over a period of two years (May 2010, August 2010, January 2011 and July 2011).

\section{Bacteriological analyses}

Composite milk samples $(40 \mathrm{~mL})$ from four mammary gland quarters of each selected cow were collected aseptically in a sterile vial before milking. The milk samples were immediately cooled

Table 1. Number of dairy herds and cows selected, according to the prevalence of Staphylococcus aureus antimicrobial resistance to penicillin

\begin{tabular}{cccc}
\hline \multirow{2}{*}{$\begin{array}{c}\text { Number of } \\
\text { lactating cows }\end{array}$} & Herd & \multicolumn{2}{c}{ Number of selected } \\
\cline { 3 - 4 } frequency (\%) & Dairy herds & Cows $\dagger$ \\
\hline $10-19$ & 29 & 6 & All cows \\
$20-29$ & 13 & 3 & All cows \\
$30-39$ & 8 & 2 & All cows or 30 if $>30$ \\
$40-49$ & 2 & 0 & - \\
$50-60$ & 4 & 1 & 30 (randomization) \\
$>60$ & 4 & 1 & 30 (randomization) \\
Total & 60 & 13 & -
\end{tabular}

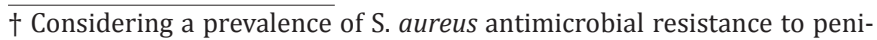
cillin of 35\% (90\% confidence interval: 33.4-36 (Britto et al. 1999). 
to $4^{\circ} \mathrm{C}$, transported to the laboratory and stored at $-20^{\circ} \mathrm{C}$. Microbiological analyses of the milk samples were performed as recommended by the National Mastitis Council (Oliver et al. 2004). A total of $10 \mu \mathrm{l}$ of milk was plated on $5 \%$ sheep blood agar and incubated at $37^{\circ} \mathrm{C}$ for 24 and 48 hours. The bacteriological cultures were classified as positive based on the presence of three or more identical colonies. The colony morphology and Gram-stain reaction of the bacterial isolates were analyzed. In the case of Gram-positive isolates, the catalase test was performed to distinguish Streptococcus spp. from Staphylococcus spp. In the case of Staphylococci, the coagulase test was performed to classify the bacteria as coagulase positive or negative, and Voges-Proskauer test was performed on the coagulase positive Staphylococcus to identify $S$. aureus. All of the bacterial isolates were cryopreserved in brain heart infusion broth (BHI, Becton, Dickinson and Company, Sparks, MD, USA) with $20 \%$ glycerol at $-20^{\circ} \mathrm{C}$ for further analyses.

\section{Antimicrobial susceptibility testing}

The antimicrobial susceptibility tests of all of the Staphylpococcus aureus isolates were performed using agar dilution as described by the Clinical and Laboratory Standards Institute (CLSI 2008). In brief, the isolates were inoculated in BHI broth and incubated for 24 hours at $36^{\circ} \mathrm{C}$; subsequently, the turbidity of the cultures were standardized 0.5 on the MacFarland scale. All the standardized bacterial suspensions were plated over the entire surface of a plate of Mueller-Hinton agar using a sterile swab. Twelve antimicrobial discs (Oxoid, Basingstoke, England) were deposited on the medium with the aid of a dispenser (Oxoid, Basingstoke, England). The plates were incubated at $35^{\circ} \mathrm{C}$, and the inhibition zones were measured after 18 hours of incubation. The inhibition zones were recorded in millimeters and were interpreted according to the criteria of the CLSI (2008). Quality control was also performed in accordance with Clinical and Laboratory Standards Institute guidelines using S. aureus ATCC 25923 and ATCC 29213, Escherichia coli ATCC 25922, Pseudomonas aeruginosa ATCC 27853, Enterococcus faecalis ATCC 29212 and Streptococcus pneumoniae ATCC 49619.

The following antimicrobials were tested: ampicillin $10 \mathrm{mg}$, clindamycin $2 \mu \mathrm{g}$, penicillin $1 \mu \mathrm{g}$, ceftiofur $30 \mu \mathrm{g}$, gentamicin $10 \mathrm{mg}$, sulfa-trimethoprim $25 \mathrm{mcg}$, enrofloxacin $5 \mu \mathrm{g}$, sulfonamide $300 \mu \mathrm{g}$, tetracycline $30 \mu \mathrm{g}$, oxacillin $1 \mu \mathrm{g}$, cephalothin $30 \mu \mathrm{g}$ and erythromycin $5 \mu \mathrm{g}$.

\section{Questionnaire about mastitis treatment and management practices}

Previously formulated questionnaires were submitted to the dairy herd manager during the first farm visit, which included questions about the following: the use of dry cow therapy; the mastitis treatment records; the use of treatment for clinical mastitis cases; the therapeutic treatment record; the use and frequency of microbiological culture tests; and the use and frequency of antimicrobial susceptibility tests of the mastitis pathogens that were identified. The following additional information about the general herd characteristics was recorded: identification and location; number of lactating cows; total milk production; individual milk yield, and milking system.

\section{Statistical analyses}

The statistical analyses were performed using the Statistical Analysis System (SAS Institute Inc. 2010). The frequencies S. aureus isolates resistance was calculated using the chi-square test (PROC FREQ). Also, the frequencies of responses to the questionnaire for each antimicrobial that had been tested were analyzed using the chi-square test (PROC FREQ), considering a probability of $\leq 0.2$ to screen for potential risk factors for the antimicrobial resistance of $S$. aureus that could be inserted into the logistic regression models. The other criteria that were used to select the variables for inclusion in the logistic regression model were those that offered a coherent biological explanation for an increase in $S$. aureus antimicrobial resistance. A multivariate logistic regression model (PROC LOGIT) was used determine risk factors at $S$. aureus positive samples level as described by Frankena \& Graat (1997), using a probability of $\leq 0.05$. The odds ratios were estimated using the respective confidence interval (CI) of $95 \%$.

\section{RESULTS}

In this study, $77 \%$ of the herds that were evaluated were composed of crossbred cows (Holstein x Gir) and were composed of $23 \%$ of Holstein cows. The number of lactating cows ranged from 11 to $90 /$ herd and the milk yield ranged from 80 to 1000 liters/day / herd. Regarding the management characteristics, manual milking was performed in four herds and mechanical milking was performed in 56 herds.

A total of 1069 milk samples were collected and subjected to microbiological culture. Of these, 756 samples (70.7\%) were culture-positive and 313 (29.3\%) were culture-negative. The frequencies with which the mastitis-causing pathogens were isolated are as follows: $28.57 \%$ of coagulase-negative Staphylococcus (CNS) ( $\mathrm{n}=216) ; 27.77 \%$ of $S$. aureus $(\mathrm{n}=210) ; 10.97 \%$ of Corynebacterium spp. $(\mathrm{n}=83) ; 8 \%$ of Streptococcus agalactiae $(\mathrm{n}=60) ; 6.2 \%$ of Streptococcus dysgalactiae $(\mathrm{n}=47) ; 6 \%$ of coagulase-positive Staphylococcus $(\mathrm{n}=45) ; 3.2 \%$ of esculin-positive Streptococcus $(\mathrm{n}=24) ; 4.9 \%$ of Arcanobacterium spp. $(\mathrm{n}=37)$, and $2.5 \%$ of Bacillus spp. $(\mathrm{n}=19)$.

The on-farm potential risk factors for $S$. aureus antimicrobial resistance according to the antimicrobial tested that were inserted into the final logistic regression model are presented in Table 2. The following risk factors for the antimicrobial resistance of $S$. aureus were identified (Table 3): ampicillin- treatment of clinical mastitis cases ( $\mathrm{OR}=2.18)$ and not sending milk samples for microbiological culture and antimicrobial susceptibility tests (OR=2.57); enrofloxacin- dry cow treatment $(\mathrm{OR}=2.11)$; penicillin- not sending milk samples for microbiological culture and antimicrobial susceptibility tests (OR=4.69).

The risk of $S$. aureus resistance on farms that did not send samples for culture and susceptibility tests was also higher for penicillin (OR=4.69) and ampicillin (OR=2.57) compared with $S$. aureus isolated from farms that performed this practice. In this study, the treatment of mastitis was identified as a risk factor for $S$. aureus resistance to ampicillin. $S$. aureus isolates from farms on which all of the clinical mastitis cases were routinely treated were 2.18 times more likely to be resistant to ampicillin than were $S$. aureus isolates from farms on which clinical mastitis was not treated. Additionally, the practice of dry cow treatment was identified as a risk factor for $S$. aureus resistance to enrofloxacin and penicillin. Farms using dry cow treatment had 2.11 times greater chances to have $S$. aureus that was resistant to enrofloxacin than did farms where this practice was not employed.

On the other hand, a protective factor identified in this study for $S$. aureus antimicrobial resistance was not using 
Table 2. Staphylococcus aureus antimicrobial resistance frequencies according to antimicrobial and evaluated risk factors

\begin{tabular}{|c|c|c|c|c|}
\hline Antimicrobial & Total of resistant (\%) & Questionnaire questions & Resistant (\%) & $\mathrm{P} \dagger$ \\
\hline \multirow[t]{2}{*}{ Ampicillin } & $71(33.8)$ & Use of clinical mastitis treatment & $56(78.9)$ & 0.005 \\
\hline & & $\begin{array}{l}\text { Not sending milk samples for microbiological } \\
\text { culture and susceptibility tests }\end{array}$ & $56(78.9)$ & 0.003 \\
\hline \multirow[t]{2}{*}{ Ceftiofur } & $57(27.1)$ & Use of clinical mastitis treatment & $43(75.4)$ & 0.048 \\
\hline & & Not respecting the withdrawal periods & $46(80.7)$ & 0.011 \\
\hline Enrofloxacin & $34(16.2)$ & Use of dry cow treatment & $17(50.0)$ & 0.049 \\
\hline \multirow[t]{2}{*}{ Erythromycin } & $10(4.8)$ & $\begin{array}{l}\text { Not sending milk samples for microbiological } \\
\text { culture and susceptibility tests }\end{array}$ & $7(70.0)$ & 0.070 \\
\hline & & Not using a mastitis treatment protocol & $7(70.0)$ & 0.165 \\
\hline \multirow[t]{2}{*}{ Gentamicin } & $38(18.1)$ & Use of clinical mastitis treatment & $29(76.3)$ & 0.145 \\
\hline & & Not keeping records of mastitis treatment & $32(84.2)$ & 0.189 \\
\hline \multirow[t]{3}{*}{ Oxacillin } & $25(11.9)$ & Use of clinical mastitis treatment & $13(52.0)$ & 0.110 \\
\hline & & Use of dry cow treatment & $6(24.0)$ & 0.066 \\
\hline & & Not using a mastitis treatment protocol & $18(72.0)$ & 0.013 \\
\hline \multirow[t]{5}{*}{ Penicillin } & $60(28.6)$ & Use of clinical mastitis treatment & $34(56.7)$ & 0.065 \\
\hline & & Use of dry cow treatment & $39(50.0)$ & 0.016 \\
\hline & & $\begin{array}{l}\text { Not sending milk samples for microbiological } \\
\text { culture and susceptibility tests }\end{array}$ & $50(83.3)$ & 0.178 \\
\hline & & Not using a mastitis treatment protocol & $39(65.0)$ & 0.003 \\
\hline & & Not keeping records of mastitis treatment & $58(96.7)$ & 0.042 \\
\hline \multirow[t]{3}{*}{ Sulfa-trimethoprim } & 35 (16.7) & Use of clinical mastitis treatment & $17(50.0)$ & 0.029 \\
\hline & & $\begin{array}{l}\text { Not sending milk samples for microbiological } \\
\text { culture and susceptibility tests }\end{array}$ & $33(97.1)$ & 0.078 \\
\hline & & Not using a mastitis treatment protocol & $20(61.8)$ & 0.093 \\
\hline \multirow[t]{2}{*}{ Sulfonamide } & $30(14.3)$ & Use of clinical mastitis treatment & $17(56.67)$ & 0.004 \\
\hline & & Not using a mastitis treatment protocol & $19(63.3)$ & 0.081 \\
\hline \multirow[t]{4}{*}{ Tetracycline } & $19(9.0)$ & Use of dry cow treatment & $11(57.9)$ & 0.115 \\
\hline & & $\begin{array}{l}\text { Not sending milk samples for microbiological } \\
\text { culture and susceptibility tests }\end{array}$ & $11(57.9)$ & $<0.001$ \\
\hline & & Not respecting the withdrawal periods & $4(21.0)$ & 0.115 \\
\hline & & Not using a mastitis treatment protocol & $12(63.2)$ & 0.182 \\
\hline
\end{tabular}

$\uparrow \mathrm{P}=$ probability calculated using the chi-squared test.

a mastitis treatment protocol for clinical mastitis cases. $S$. aureus isolates from farms that did not use this treatment protocol were 0.45 times more likely to be resistant to tetracycline than were $S$. aureus isolates from farms that used a mastitis treatment protocol. The factors that showed a odds ratio $<1$ were considered as protective factors.

\section{DISCUSSION}

This study evaluated the association between herd management and the treatment practices for mastitis in dairy cows and the resistance of Staphylococcus aureus to antimicrobial agents. According to the logistic regression model, the OR of Staphylococcus aureus resistance to penicillin and ampicillin was higher on farms that did not sendi milk samples for microbiological culture and susceptibility tests. Hoe \& Ruegg (2006) reported that the use of microbiological culture testing for mastitis diagnosis was also associated with the size of the herd. These authors reported a total of $38.9 \%$ of the farms with large herds had culture tests performed for all of the clinical mastitis cases, compared with the farms with smaller herds. On farms with medium and large herds, it was 2-3 times more likely that bulk tank cultures to identify mastitis pathogens were performed compared with on farms with smaller herds, and $49 \%$ of the farms with smaller herds had never had microbiological bulk tank cultures conducted. According to Hoe \& Ruegg (2006), the larger farms had more access to bulk tank diagnostic methods than did the farms with smaller herds.

The practice of dry cow treatment was identified as a risk factor for $S$. aureus resistance to enrofloxacin. Studies of the association between dry cow therapy and the development of antimicrobial resistance in mastitis pathogens are limited. Pol \& Ruegg (2007) evaluated the relationship between antimicrobial use and the susceptibility of Gram-positive mastitis pathogens in organic and conventional dairy herds. In that study, the antimicrobials that were most frequently used for dry cow treatment were penicillin, streptomycin and tetracycline (90\%), and the daily doses of these antimicrobials was calculated at the mammary quarter level. $S$. aureus isolates from the conventional herds were 7.7 times more likely to be resistant to ampicillin and 6.3 times more likely to be resistant to penicillin compared to the isolates from the organic farms (Pol \& Ruegg 2007). The differences in the resistance on the conventional farms were attributed to the intramammary treatment of clinical mastitis (66\%) and dry cow treatment (44\%). In addition, the isolates from multiparous cows were more likely to be resistant than were the isolates from primiparous cows. These observations suggested that long-term exposure to antimicrobials (for example, continuous use of dry cow treatment) significantly increases the level of antimicrobial resistance (Pol \& Ruegg 2007), as observed in the present study. 
Table 3. Risk factors associated with Staphylococcus aureus antimicrobial resistance as estimated using logistic regression

\begin{tabular}{llccc}
\hline Antimicrobial & \multicolumn{1}{c}{ Risk factors } & OR† & $95 \% \mathrm{CI}^{\ddagger}$ & $\mathrm{P}^{\S}$ \\
\hline Ampicillin & $\begin{array}{l}\text { Use of clinical mastitis treatment } \\
\text { Not sending milk samples for microbiological } \\
\text { culture and susceptibility tests }\end{array}$ & 2.18 & $1.10-4.32$ & 0.026 \\
Enrofloxacin & Use of dry cow treatment & $1.06-6.24$ & 0.037 \\
Penicillin & $\begin{array}{l}\text { Not sending milk samples for microbiological } \\
\text { culture and susceptibility tests }\end{array}$ & 4.69 & $1.01-4.44$ & 0.049 \\
& & & & \\
\hline † OR = odds ratio, $\neq \mathrm{CI}=$ confidence interval, ${ }^{\S} \mathrm{P}=$ probability. & & &
\end{tabular}

Rajala-Schultz et al. (2009) determined both the prevalence of antimicrobial resistance of coagulase-negative staphylococci (CNS) isolates before and after dry cow treatment and the diversity and persistence of this group of microorganisms during the dry cow period. These authors reported a strong association between antimicrobial resistance to most beta-lactam antibiotics and the age of the animals, dry cow treatment, high somatic cell counts and a history of clinical mastitis. Similarly, in the present study, one of the main risk factors for the antimicrobial resistance of $S$. aureus was dry cow treatment.

Treatment of mastitis is the major reason for antimicrobial use in dairy herds (Sawant et al. 2005). Guidelines on the prudent and judicious use of antimicrobials have recently been developed by international organizations, including the World Health Organization (WHO) and the International Organization of Epizooties (OIE 2008). As part of good veterinary practice, these guidelines aim to maximize therapeutic efficacy and minimize the selection of resistant organisms. Sawant et al. (2005) described some of these practices, including record keeping and the treatment protocols for cases of mastitis.

In this study, the practice of not using a mastitis treatment protocol for clinical mastitis cases was identified as a protective factor identified for $S$. aureus tetracycline resistance. According to Hoe \& Ruegg (2006), written treatment protocols are recommended to establish practices and treatment decisions. In a study that Hoe \& Ruegg (2006) conducted in Wisconsin (USA), a written protocol for the treatment of mastitis was highly associated with the herd size $(\mathrm{P}<0.001)$. Most of the farmers in that study had large herds $(75 \%)$ and reported that they maintained a written protocol for the treatment of mastitis, compared with 29 and $21 \%$ of the farmers with medium or small herds, respectively. Regardless of the herd size, $60 \%$ of the treatment protocols were written by a veterinarian, approximately $30 \%$ of the treatment protocols were written by farm managers and less than $1 \%$ of the treatment protocols were from the pharmaceutical companies.

Some of the limitations of the present study were the small number of herds sampled $(n=13)$ and the small number of variables tested $(n=6)$. Therefore, careful consideration should be taken when comparing the data presented in this study with the data from other studies. Additionally, the results of this study are from a specific Brazilian region and may be not representative of the entire country. Thus, future studies may discover the profile of trends in antimicrobial resistance in Brazilian dairy herds.
There was an association between the resistance of $S$. aureus to antimicrobials and the management practices and mastitis treatment on the farms. The results of the present study suggest that the frequency of Staphylococcus aureus resistance is greater for ampicillin than other antimicrobial tested. Additionally, Staphylococcus aureus resistance for penicillin is higher in dairy farms that do not send milk samples for microbiological culture and susceptibility tests. The identification of risk factors for $S$. aureus resistance against various mastitis antimicrobials is an important information that helps in practical recommendations for a prudently antimicrobial use in milk production.

Acknowledgment.- The authors are grateful to 'Empresa Brasileira de Agropecuária' (Embrapa) and 'Conselho Nacional de Desenvolvimento Científico e Tecnológico' (CNPq) for research funding (578430/2008-8) and to José Garcia Moreno Franchini and Lucinéia Mestieri for technical assistance.

\section{REFERENCES}

Acar J.F. \& Moulin G. 2006. Antimicrobial resistance at farm level. Rev. Sci. Tech. 25:775-792.

Brito M.A.V.P., Brito J.R.F., Ribeiro M.T. \& Veiga V.M.O. 1999. Padrão de infecção intramamária em rebanhos leiteiros: exame de todos os quartos mamários das vacas em lactação. Arq. Bras. Med. Vet. Zootec. 51:129-135.

Clinical and Laboratory Standards Institute 2008. Performance Standards for Antimicrobial Susceptibility Testing; Eighteenth Informational Supplement. CLSI Document M100-S18. Clinical and Laboratory Standards Institute, Wayne, PA.

Erskine R.J., Walker R.D., Bolin C.A., Bartlett P.C. \& White D.G. 2002. Trends in antibacterial susceptibility of mastitis pathogens during a seven-year period. J. Dairy Sci. 85:1111-1118.

Frankena K. \& Graat E.A.M. 1997. Multivariate analysis: logistic regression, p.135-178. In: Noordhuizen J.P.T.M., Frankena K., Thrusfield M.V. \& Graat E.A.M. (Eds), Apllication of quantitative methods in veterinary epidemiology. $2^{\text {nd }}$ ed. Wageningen Pers, Wageningen, Netherlands.

Freitas M.F.L., Pinheiro Junior J.W., Stamford T.L.M., Rabelo S.S.A., Silva D.R., Silveira Filho V.M., Santos F.G.B. \& Mota R.A. 2005. [Profile of in vitro antimicrobial susceptibility of coagulase positive isolates from milk of cows with mastitis in rural Pernambuco State]. Arqs Inst. Biológico, São Paulo, 72:171-177.

Guler L., Ok U., Gunduz K., Gulcu Y. \& Hadimli H.H. 2005. Antimicrobial susceptibility and coagulase gene typing of Staphylococcus aureus isolated from bovine clinical mastitis cases in Turkey. J. Dairy Sci. 88:3149-3154.

Hawkey P.M. 2003. Mechanisms of quinolone action and microbial response. J. Antimicrob. Chemother. 51:29-35.

Hoe F.G. \& Ruegg P.L. 2006. Opinions and practices of wisconsin dairy producers about biosecurity and animal well-being. J. Dairy Sci. 89:22972308.

Makovec J.A. \& Ruegg D.P.L. 2003. Antimicrobial resistance of bacteria isolated from dairy cow milk samples submitted for bacterial culture: 8,905 samples (1994-2001). J. Am. Vet. Med. Assoc. 222:1582-1589. 
Malinowski E., Klossowska A., Kaczmarowski M., Lassa H. \& Kuzma K. 2002. Antimicrobial susceptibility of staphylococci isolated from affected with mastitis cows. Bull. Vet. Inst. Pulawy 46:289-294.

Myllys V., Asplund K., Brofeldt E., Hirvela-Koski V., Honkanen-Buzalski T., Junttila J., Kulkas L., Myllykangas O., Niskanen M., Saloniemi H., Sandholm M. \& Saranpaa T. 1998. Bovine mastitis in Finland in 1988 and 1995-changes in prevalence and antimicrobial resistance. Acta Vet. Scand. 39:119-126

OIE 2008. Harmonisation of national antimicrobial resistance surveillance and monitoring programs, p.1-7. In: World Organization for Animal Health (Ed.), Terrestrial Animal Health Code. OIE, Paris.

Oliver S.P., Hogan J.S., Jayarao B.M. \& Owens W.E. 2004. Microbiological Procedures for the Diagnosis of Bovine Udder Infection and Determination of Milk Quality. $4^{\text {th }}$ ed. National Mastitis Council Inc., Verona, WI.

Oliver S.P. \& Murinda S.E. 2012. Antimicrobial resistance of mastitis pathogens. Vet. Clin. North. Am., Food Anim. Pract. 28:165-185.

Oliver S.P., Murinda S.E. \& Jayarao B.M. 2011. Impact of antibiotic use in adult dairy cows on antimicrobial resistance of veterinary and human pathogens: a comprehensive review. Foodborne Pathog. Dis. 8:337355.

Petrovski K.R., Laven R.A. \& Lopez-Villalobos N. 2011. A descriptive analysis of the antimicrobial susceptibility of mastitis-causing bacteria isolated from samples submitted to commercial diagnostic laboratories in New Zealand (2003-2006). N. Z. Vet. J. 59:59-66.

Pol M. \& Ruegg P.L. 2007. Relationship Between Antimicrobial Drug Usage and Antimicrobial Susceptibility of Gram-Positive Mastitis Pathogens. J. Dairy Sci. 90:262-273.
Rajala-Schultz P.J., Torres A.H., DeGraves F.J., Gebreyes W.A. \& Patchanee P. 2009. Antimicrobial resistance and genotypic characterization of coagulase-negative staphylococci over the dry period. Vet. Microbiol. 134:55-64.

Roberson J.R., Fox L.K., Hancock D.D., Gay J.M. \& Besser T.E. 1994. Ecology of Staphylococcus aureus isolated from various sites on dairy farms. J. Dairy Sci. 77:3354-3364.

Ruegg P.L. 2009. Management of mastitis on organic and conventional dairy farms. J. Anim Sci. 87:43-55.

Sabour P.M., Gill J.J., Lepp D., Pacan J.C., Ahmed R., Dingwell R. \& Leslie K. 2004. Molecular Typing and Distribution of Staphylococcus aureus isolates in Eastern Canadian dairy herds. J. Clin. Microbiol. 42:3449-3455.

Sampimon O., Barkema H.W., Berends I., Sol J. \& Lam T. 2009. Prevalence of intramammary infection in Dutch dairy herds. J. Dairy Res. 76:129-136.

Sawant A.A., Sordillo L.M. \& Jayarao B.M. 2005. A survey on antibiotic usage in dairy herds in Pennsylvania. J. Dairy Sci. 88:2991-2999.

Statistical Analisys System 2010. SAS User's Guide: statistics. Versão 9.22. SAS Institute Inc., Cary.

Waage S. 1997. Comparison of two regimens for the treatment of clinical bovine mastitis caused by bacteria sensitive to penicillin. Vet. Rec. 141:616-620.

Wang Y., Wu C.M., Lu L.M., Ren G.W., Cao X.Y. \& Shen J.Z. 2008. Macrolide-lincosamide-resistant phenotypes and genotypes of Staphylococcus aureus isolated from bovine clinical mastitis. Vet. Microbiol. 130:118-125.

Watts J.L. \& Salmon S.A. 1997. Activity of selected antimicrobial agents against strains of Staphylococcus aureus isolated from bovine intramammary infections that produce $\beta$-lactamase. J. Dairy Sci. 80:788-791. 